Molecules 2011, 16, 7043-7057; doi:10.3390/molecules16087043

\title{
Development of a Highly Sensitive and Specific Immunoassay for Determining Chrysoidine, A Banned Dye, in Soybean Milk Film
}

\author{
Hongtao Lei ${ }^{1}$, Jin Liu ${ }^{1}$, Lijun Song ${ }^{1}$, Yudong Shen ${ }^{1}$, Simon A. Haughey ${ }^{2}$, Haoxian Guo ${ }^{1}$, \\ Jinyi Yang ${ }^{1}$, Zhenlin Xu ${ }^{1}$, Yueming Jiang ${ }^{3, *}$ and Yuanming Sun ${ }^{1, *}$ \\ 1 Guangdong Provincial Key Laboratory of Food Quality and Safety, South China Agricultural \\ University, Guangzhou 510642, Guangdong, China; E-Mails: hongtao@scau.edu.cn (H.L.); \\ liujin_001163@163.com (J.L.); songlijun0703330@163.com (L.S.); \\ shenyudong@scau.edu.cn (Y.S.); ghxghz@sina.com (H.G.); yjy361@163.com (J.Y.); \\ jallent@163.com (Z.X.)
}

2 Institute of Agri-Food and Land Use, Queen's University Belfast, Belfast BT9 5AG, Northern Ireland, UK; E-Mail: s.a.haughey@qub.ac.uk (S.A.H.)

3 Key Laboratory of Plant Resources Conservation and Sustainable Utilization, South China Botanical Garden, Chinese Academy of Sciences, Guangzhou 510650, Guangdong, China

* Authors to whom correspondence should be addressed; E-Mails: ymjiang@scbg.ac.cn (Y.J.); ymsun@scau.edu.cn (Y.S.); Tel.: +8620-37252525 (Y.J.); +8620-8528-3925 (Y.S.); Fax: +8620-37252960 (Y.J.); Fax: +8620-85280270 (Y.S.).

Received: 18 July 2011; in revised form: 7 August 2011 / Accepted: 11 August 2011 / Published: 17 August 2011

\begin{abstract}
A highly specific and sensitive indirect competitive enzyme-linked immunosorbent assay (icELISA) was developed for the first time for the detection of chrysoidine, a dye banned in soybean milk film. Two haptens with different spacer arms were synthesized to produce antibodies. Both homologous and heterologous immunoassay formats were compared to enhance the icELISA sensitivity. The heterologous icELISA exhibited better performance, with an $\mathrm{IC}_{50}(50 \%$ inhibitory concentration) of $0.33 \mathrm{ng} / \mathrm{mL}$, a limit of detection (LOD, 10\% inhibitory concentration) of $0.04 \mathrm{ng} / \mathrm{mL}$, and a limit of quantitation (LOQ, 20\%-80\% inhibitory concentration) from 0.09 to $4.9 \mathrm{ng} / \mathrm{mL}$. The developed icELISA was high sensitive and specific, and was applied to determine chrysoidine in fortified soybean milk film samples. The results were in good agreement with that obtained by high-performance liquid chromatography (HPLC) analyses.
\end{abstract}


Keywords: chrysoidine; antibody; ELISA; soybean milk film

\section{Introduction}

Chrysoidine (C.I. Basic Orange 2, Figure 1) is a type of industrial azoic dye [1]. Due to its good dyeing fastness, it is widely used for dyeing leather, paper, feather, grass, wood, bamboo, etc. [2]. Chrysoidine can cause acute and chronic toxicity to mammals when taken by oral or skin route, or inhaled, and its median lethal concentration $\left(\mathrm{LC}_{50}, 24 \mathrm{~h}\right)$ for fish was $0.5 \mathrm{mg} / \mathrm{L}$ [3]. Chrysoidine has also been recognized as a carcinogen [4] and its use in food has not been approved by any country. Unfortunately, it has been reported that soybean milk film, a popular soybean food consumed in China was adulterated with chrysoidine [5,6]. Moreover, chrysoidine has also been found in yellow-fin tuna and dried bean curd stick [2,7]. Therefore, control of this banned dye in food is very crucial and the development of a simple, economic, and rapid detection method is urgently needed.

Figure 1. Structure of chrysoidine.

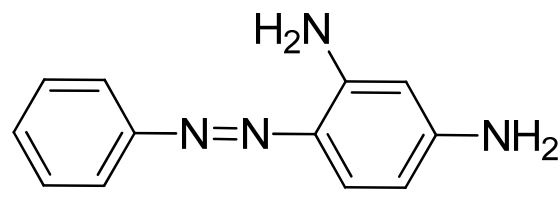

The reported analyses of chrysoidine were mainly physio-chemical methods based on chromatography with various detectors $[2,4,5,8,9]$. The detection limit of chrysoidin in a HPLC-MS study was $0.25 \mathrm{ng} / \mathrm{g}$ [4], and $2.3 \mathrm{ng} / \mathrm{g}$ in a GC-MS method [8]. Chromatography methods can provide accurate and reliable results, but these methods are also expensive, laborious and time-consuming [10]. To date, immunoassay technologies, especially ELISA, are increasingly replacing traditional chemical analyses in screening of food contaminants and agrochemicals due to their sensitivity, time-efficiency and cost-effectiveness [11-13]. ELISAs have been widely used for the determination of various contaminants such as toxins [14,15], drugs [16,17], pesticides [18] and illegal additives [11,12] in the biological, agriculture, and environmental fields. However, to the best of our knowledge, there is no published literature on an immunoassay for the detection of chrysoidine.

In this study, a highly sensitive and specific ELISA for the determination of chrysoidine was developed for the first time. Two chrysoidine haptens with different spacer arm lengths were synthesized and covalently coupled to different carrier proteins to produce both immunogens and coating antigens. The polyclonal antibody ( $\mathrm{pAb}$ ) to chrysoidine raised from immunized rabbits were characterized and used for a competitive ELISA. The developed ELISA was further employed to analyze spiked soybean milk film samples and validated by a HPLC method. 


\section{Results and Discussion}

\subsection{Synthesis of Chrysoidine Haptens}

For production of high quality antibodies and development of highly sensitive and specific immunoassays, it is important to design a proper hapten structure. It was proposed that both the conjugation position at the hapten molecule where the spacer is attached and the length of the spacer may play an important role for a successful antibody production [11,19], and that the molecular structure of the hapten should be left unchanged [20]. In this study two chrysoidine-derivatives with different spacer lengths were synthesized (Scheme 1). One derivative with one carbon-atom spacer length (Hapten 1) and the other with two-carbon-atom spacer length (Hapten 2) were modified at the para position of the azo bond. The structures of Hapten 1 and Hapten 2 were confirmed by thin layer chromatography (TLC), mass spectrometry (MS) and nuclear magnetic resonance (NMR) methods.

Scheme 1. Synthesis of chrysoidine haptens.
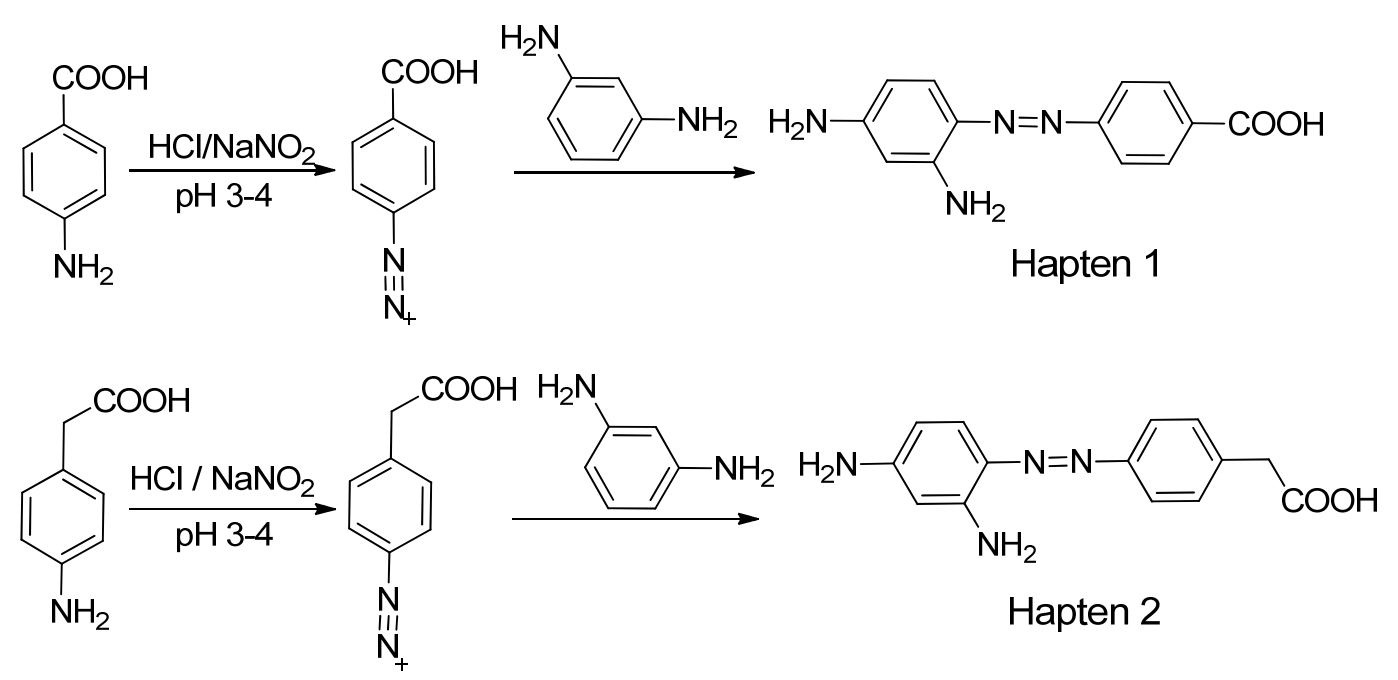

\subsection{Synthesis of Immunogen and Coating Antigen}

The chrysoidine derivative bearing a carboxylic acid group at the end of the spacer was activated by the active ester method and then covalently coupled with a carrier protein (BSA or OVA) [21]. The conjugates of hapten-BSA and hapten-OVA were used as immunogen and coating antigen, respectively. Figure 2 shows the UV spectra of BSA, OVA, Hapten 1, Hapten 1-BSA and Hapten 1-OVA with absorption peaks of Hapten 1, BSA and OVA at 450, 280 and $280 \mathrm{~nm}$, respectively. The absorption spectra of Hapten 1-BSA/OVA conjugates contain both absorption peaks of Hapten1 and BSA/OVA, but with somewhat red shift. The results indicated that the coupling of hapten to BSA and OVA was successful. Similar results were obtained with Hapten 2 conjugate (data not shown). 
Figure 2. UV spectra of BSA, OVA, Hapten 1, Hapten 1-BSA and Hapten 1-OVA.

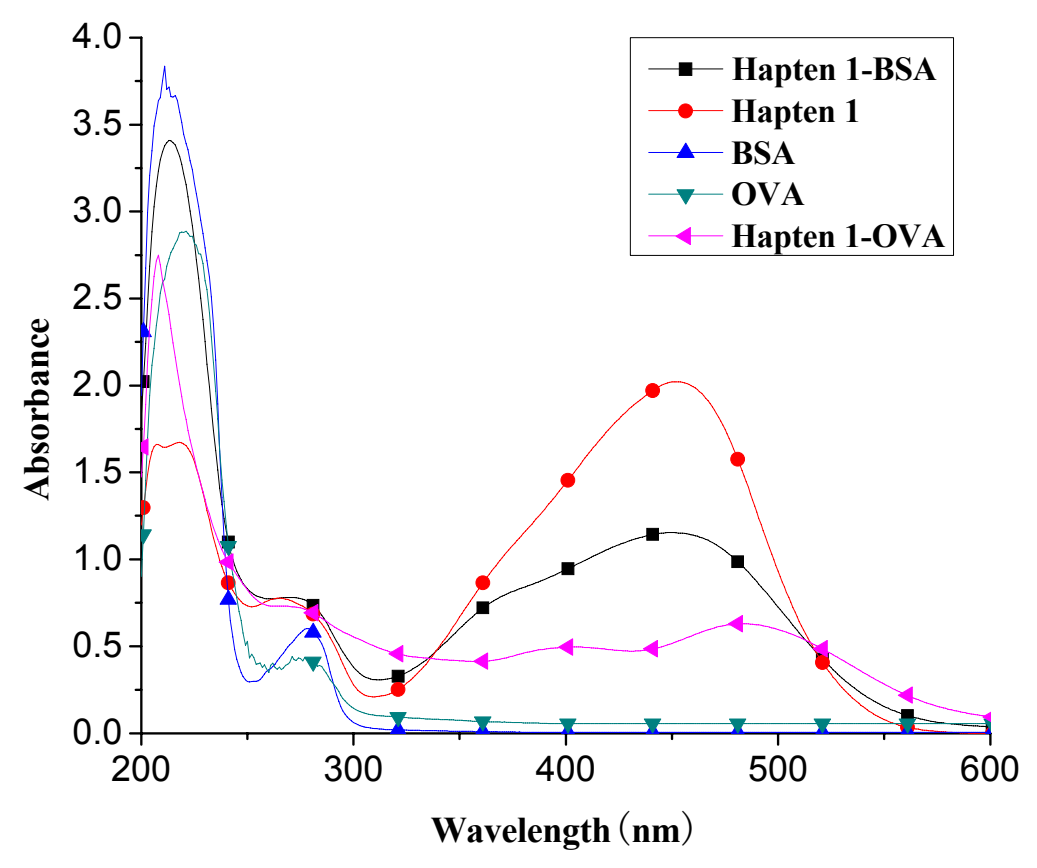

\subsection{Optimization of icELISA Conditions}

The prepared coating antigens were used for the icELISA assay. To improve the sensitivity of icELISA, we have optimized the assay conditions by changing the assay format, concentration of the coating antigen, dilution of the antiserum and antigen antibody reaction time. Two criteria were used for optimizing the icELISA assay. (1) obtain a minimum $\mathrm{IC}_{50}$ value and (2) increase an absorbance to 0.8-1.5 units for the zero standard concentration (blank) [22].

The antisera collected after each boost were subject to titration and inhibition by the homology indirect and competitive ELISA, respectively. All antisera showed relatively constant high titer and inhibition ratio after the sixth immunization. Therefore, combinations of two different coating antigens (Hapten 1-OVA and Hapten 2-OVA) and two antibodies (Ab 1 from Hapten 1 and Ab 2 from Hapten 2) were tested. The experimental conditions, including coating antigen concentration and antiserum dilution, were optimized for each combination (Table 1). In specific, coating antigen concentration and antiserum varied in the range of $17-20 \mathrm{ng} / \mathrm{mL}$ and 1:4,000-1:20,000, respectively. The calculated $\mathrm{IC}_{50}$ values were found to be less than $11 \mathrm{ng} / \mathrm{mL}$. With an $\mathrm{IC}_{50}$ of $0.33 \mathrm{ng} / \mathrm{mL}$, the combination of hapten 1-OVA and $\mathrm{Ab} 2$ was found to be most sensitive. With this combination the typical standard curve for chrysoidine were constructed in the concentration range from 0.09 to $4.9 \mathrm{ng} / \mathrm{mL}$ and the values of LOD at $10 \%$ inhibition was within $0.04 \mathrm{ng} / \mathrm{mL}$, indicating that the sensitivity was better than that of the reported physio-chemical method [4]. In addition, since both heterologous combination (Ab 1/hpaten 2-OVA and $\mathrm{Ab}$ 2/hapten 1-OVA) demonstrated lower $\mathrm{IC}_{50}$, significant differences in assay sensitivity were observed between homogeneous and heterogeneous combinations of coating antigens and antibodies (Figure 3), which implied that the heterologous plate coating antigens significantly enhanced the assay sensitivity [12]. Thus, the combination of Ab 2 and hapten 1-OVA was used for the further investigation due to its better sensitivity. 
Table 1. Optimized icELISA conditions.

\begin{tabular}{cccccc}
\hline $\begin{array}{c}\text { Coating antigen } \\
\text { name }\end{array}$ & $\begin{array}{c}\text { Coating concentration } \\
(\mathbf{n g} / \mathbf{m L})\end{array}$ & $\begin{array}{c}\text { Antibody } \\
\text { name }\end{array}$ & $\begin{array}{c}\text { Antibody } \\
\text { dilution }\end{array}$ & $\begin{array}{c}\mathbf{I C}_{\mathbf{5 0}} \\
(\mathbf{n g} / \mathbf{m L})\end{array}$ & $\begin{array}{c}\text { LOD } \\
(\mathbf{n g} / \mathbf{m L} \mathbf{)})\end{array}$ \\
\hline Hapten 1-OVA & 20 & $\mathrm{Ab} 1$ & 8000 & 7.4 & 0.8 \\
Hapten 1-OVA & 20 & $\mathrm{Ab} \mathrm{2}$ & 4000 & 0.33 & 0.04 \\
Hapten 2-OVA & 20 & $\mathrm{Ab} \mathrm{1}$ & 20000 & 1.6 & 0.4 \\
Hapten 2-OVA & 17 & $\mathrm{Ab} \mathrm{2}$ & 10000 & 10.6 & 3.8 \\
\hline
\end{tabular}

Figure 3. icELISA standard curves for chrysoidine with heterogeneous combinations of coating antigen and antibody. Data represented in mean \pm SD (standard deviation) from three assays. combination of antibody 2 and Hapten 1-OVA; • combination of antibody 1 and Hapten 2-OVA; $\boldsymbol{\Delta}$ combination of antibody 1 and Hapten 1-OVA; $\boldsymbol{\nabla}$ combination of antibody 2 and Hapten 2-OVA.

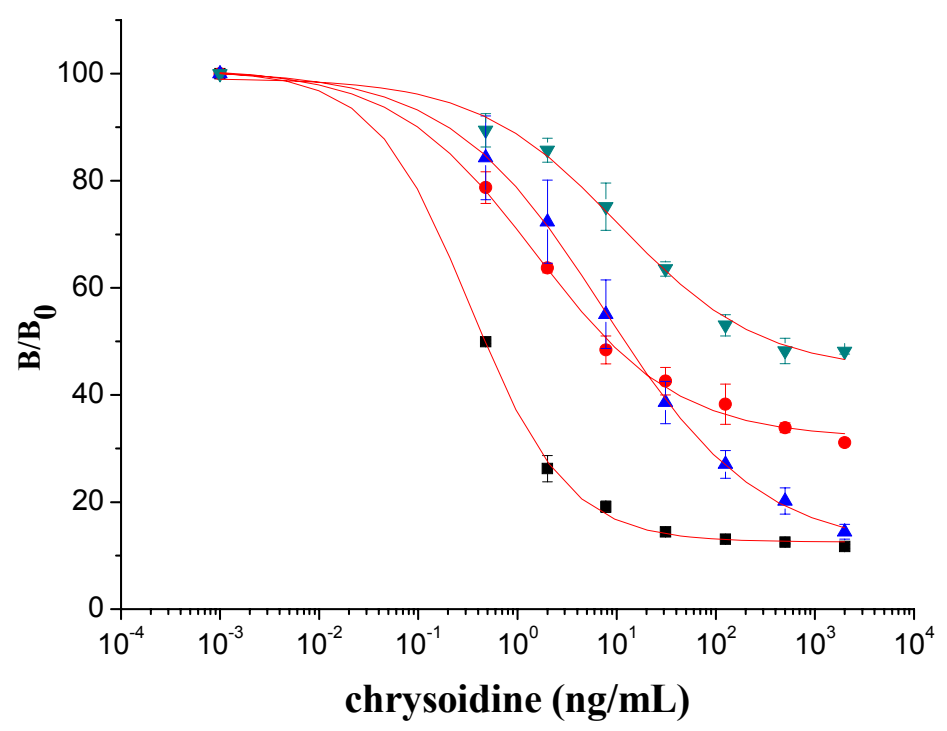

\subsection{Specificity of the icELISA}

The assay specificity was evaluated using a set of compounds structurally related to chrysoidine, and the cross-reactivity data for each compound is given in Table 2 . The highest recognition was raised from the two artificial haptens with CR values of $170 \%, 127 \%$, respectively. The high $\mathrm{CR}$ to the haptens could be explained by the similarity of the molecular structure [13]. The icELISA showed lower cross-reactivity to Acid Yellow 23, orangeim and auramine $\mathrm{O}$, the CR values were $0.04 \%, 0.12 \%$ and $0.11 \%$, respectively, which may be associated with the shared group benzene-ring, azo-bond and amino group among these compounds. From Table 2 it is also apparent that there was no cross-reactivity with other compounds, where $\mathrm{CR}$ values were less than $0.01 \%$. As expected, the major difference in the structures between chrysoidine and other dyes should be responsible for the low or no recognition [11,23-25]. Although Hapten 1 and 2 showed more than 100\% cross-reactivity, they both are artificial and, therefore, have seldom chance to occur in food to cause the matrix effects. As a result, the developed icELISA can meet the specificity requirement for the screening assay of chrysoidine. 
Table 2. Cross-reactivity of the polyclonal $\mathrm{Ab} 2$ with chrysoidine, hapten and other compounds based on coating antigen Hapten 1-OVA.

\begin{tabular}{|c|c|c|c|}
\hline Compounds & Structure & $\mathrm{IC}_{50}(\mathrm{nmol} / \mathrm{L})$ & Cross-reactivity (\%) \\
\hline Chrysoidine & & 1.33 & 100.0 \\
\hline Hapten 1 & & 0.78 & 169.8 \\
\hline Hapten2 & & 1.05 & 127.0 \\
\hline Sunset yellow & & ${ }^{\mathrm{a}} \mathrm{ND}$ & $\leq 0.01$ \\
\hline Acid Yellow 23 & & 3054.4 & 0.04 \\
\hline Orangeim & & 1121.90 & 0.1 \\
\hline Acid Red 94 & & ND & $\leq 0.01$ \\
\hline Auramine $\mathrm{O}$ & & 797.81 & 0.2 \\
\hline $\begin{array}{l}\text { 1-(4-nitrophenyl- } \\
\text { azo)-2-naphthol }\end{array}$ & & ND & $\leq 0.01$ \\
\hline Sudan Red I & & ND & $\leq 0.01$ \\
\hline Azorubine & & ND & $\leq 0.01$ \\
\hline
\end{tabular}


Table 2. Cont.

\begin{tabular}{|c|c|c|c|}
\hline Compounds & Structure & $\mathrm{IC}_{50}(\mathrm{nmol} / \mathrm{L})$ & Cross-reactivity (\%) \\
\hline Indigo & & ND & $\leq 0.01$ \\
\hline Allura Red & & ND & $\leq 0.01$ \\
\hline $\begin{array}{l}\text { Quinoline } \\
\text { yellow }\end{array}$ & & ND & $\leq 0.01$ \\
\hline Erythrosine & & ND & $\leq 0.01$ \\
\hline Tartrazine & & ND & $\leq 0.01$ \\
\hline Amaranth & & ND & $\leq 0.01$ \\
\hline Carminic acid & & ND & $\leq 0.01$ \\
\hline Scarlet Base G & & ND & $\leq 0.01$ \\
\hline $\begin{array}{l}\text { Reddish } \\
\text { orange }\end{array}$ & & ND & $\leq 0.01$ \\
\hline Carmine & & ND & $\leq 0.01$ \\
\hline $\begin{array}{l}\text { Brilliant } \\
\text { blue- } 85\end{array}$ & & ND & $\leq 0.01$ \\
\hline
\end{tabular}


Table 2. Cont.

\begin{tabular}{|c|c|c|c|}
\hline Compounds & Structure & $\mathrm{IC}_{50}(\mathrm{nmol} / \mathrm{L})$ & Cross-reactivity (\%) \\
\hline Orange yellow & & ND & $\leq 0.01$ \\
\hline $\begin{array}{c}\text { Gardenia } \\
\text { yellow }\end{array}$ & & ND & $\leq 0.01$ \\
\hline Melamine & & ND & $\leq 0.01$ \\
\hline
\end{tabular}

${ }^{\mathrm{a}} \mathrm{ND}$ represents the infinite $\mathrm{IC}_{50}$ value that could not be fitted with the four-parameter logistic equation.

\subsection{Fortification Experiment}

The performance of an immunochemical method can be significantly influenced by the various complicated matrices existing in the sample, and a dilution is usually a good way to eliminate this matrix effect [26]. The effects caused by matrix were investigated using soya milk film purchased from a local market (confirmed to be negative by HPLC). In this study, soybean milk film samples were fortified with chrysoidine at a concentration of 45-180 $\mathrm{ng} / \mathrm{g}$ and extracted with the extraction buffer $\left(0.1 \mathrm{M} \mathrm{Na}_{2} \mathrm{HPO}_{4}: \mathrm{MeOH}=60: 90, \mathrm{v}: \mathrm{v}\right)$. The absorbance of the 60 -fold diluted sample extraction was found to be almost same to that of the PBST (data not shown), indicating no obvious matrix effect. Accordingly, the 60-fold dilution was selected for the subsequent experiments. The results obtained from each spiked sample with five replicates are shown in Table 3. Recovery rates of $102.1 \%-106.5 \%$ and intra-assay coefficients of variation of $2.4-4.9 \%$ were obtained.

Table 3. Recovery of chrysoidine from the fortified samples by icELISA.

\begin{tabular}{ccccccc}
\hline $\begin{array}{c}\text { Sample } \\
\text { weight }(\mathbf{g})\end{array}$ & $\begin{array}{c}\text { Chrysoidine } \\
\text { added }(\boldsymbol{\mu g})\end{array}$ & $\begin{array}{c}\text { Fortified con. } \\
(\mathbf{n g} / \mathbf{g})\end{array}$ & $\begin{array}{c}\text { Dilution of } \\
\text { extract }\end{array}$ & $\begin{array}{c}\text { Detected } \\
(\mathbf{n g} / \mathbf{g})\end{array}$ & $\begin{array}{c}\text { Recovery } \\
(\boldsymbol{\%})\end{array}$ & $\begin{array}{c}\mathbf{C V}(\mathbf{\%}) \\
(\boldsymbol{n}=\mathbf{5})\end{array}$ \\
\hline 2.5 & 0.112 & 45 & 60 & 48 & 106.5 & 4.9 \\
2.5 & 0.225 & 90 & 60 & 92 & 102.1 & 3.4 \\
2.5 & 0.450 & 180 & 60 & 186 & 103.1 & 2.4 \\
\hline
\end{tabular}

\subsection{Validation of icELISA by HPLC}

The HPLC calibration curve for chrysoidine was constructed in the range of $0,10,20,30,90,270$, 810 and $2430 \mathrm{ng} / \mathrm{mL}$. As indicated in Figure 4, chrysoidine can be detected at the retention time of 7.0 min using HPLC. The linear equation of the HPLC standard curve was $\mathrm{Y}=122.4 \mathrm{X}-359.0\left(r^{2}=0.99\right)$. The detection and quantification limits, which were respectively defined as signal-to-noise ratio of 3:1 and 10:1, were 6.4 and $14.6 \mathrm{ng} / \mathrm{mL}$, respectively. 
Figure 4. HPLC chromatogram of chrysoidine $(10 \mathrm{ng} / \mathrm{mL})$.

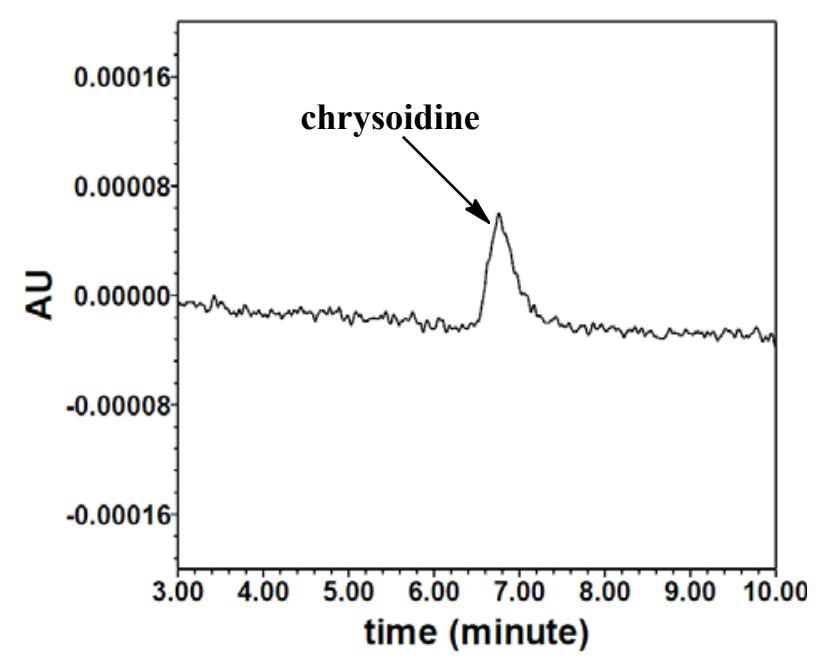

To validate the applicability of the icELISA, the fortified food samples were measured by HPLC and icELISA simultaneously. As shown in Figure 5, there is a good correlation between icELISA and HPLC with the linear regression equation of $\mathrm{Y}=1.03 \mathrm{X}-70.79\left(r^{2}=0.99, n=5\right)$. These results show that icELISA can be useful for the primary quantitative screening of chrysoidine in soybean milk film.

Figure 5. Correlation of icELISA with HPLC analysis for soybean milk film samples.

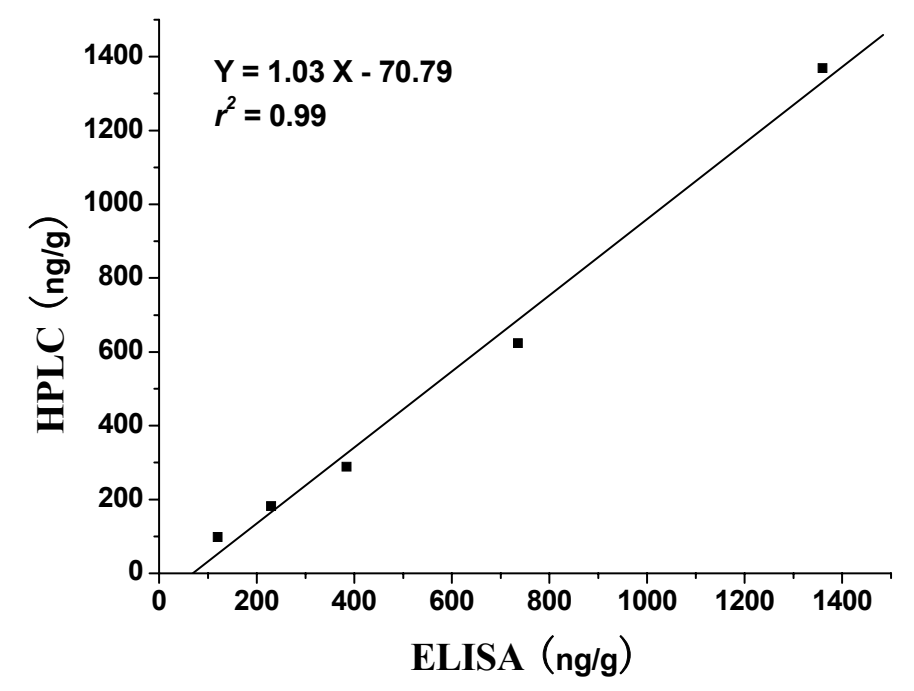

\section{Experimental}

\subsection{Reagents}

General reagents and organic solvents were of analytical grade unless specified. Chrysoidine (HPLC grade), $N, N$ '-dicyclohexylcarbodiimide (DCC), $N$-hydroxysuccinimide (NHS), 3,3',5,5'-tetramethylbenzidine (TMB), bovine serum albumin (BSA), ovalbumin (OVA), 4-aminobenzoic acid, 4-aminophenylacetic acid, 3-aminobenzoic acid, $m$-phenylenediamine, complete and incomplete Freund's adjuvants were purchased from Sigma (St. Louis, MO, USA). HRP-conjugated 
goat-anti-rabbit IgG was obtained from Boster Biotech Corporation Limited. (Wuhan, China). Polystyrene ELISA plates were provided from Jincanhua Corporation (Shenzhen, China). Tween-20, methanol (HPLC grade), dimethylformamide (DMF), dimethyl sulfoxide (DMSO) were obtained from Yunhui Company (Guangzhou, China). All structure-related compounds such as Sunset yellow, Acid Yellow 23, Orangeim, Acid Red 94, Auramine O, 1-(4-nitrophenylazo)-2-naphtho and Sudan Red I, etc., used for the cross-reactivity evaluation, were purchased from Dongzheng Chemical Corporation (Guangzhou, China). Coating buffer: $0.05 \mathrm{M}$ carbonate buffer, $\mathrm{pH}$ 9.8; Assay and washing buffer (PBST): $0.01 \mathrm{M}$ phosphate buffered saline with Tween-20, $\mathrm{pH} 7.4$, containing $145 \mathrm{mM} \mathrm{NaCl}$ and $0.05 \%$ (v:v) Tween-20; Blocking solution: 5\% (v:v) skim milk powder in distilled water; Substrate solution: $15 \mathrm{mg}$ TMB in $10 \mathrm{~mL}$ DMF, keep in dark place at $4{ }^{\circ} \mathrm{C}$; Developing buffer: $0.04 \mathrm{M} \mathrm{Na}_{2} \mathrm{HPO}_{4} \cdot 12 \mathrm{H}_{2} \mathrm{O}$ and $0.048 \mathrm{M}$ citric acid; Stop solution: sulfuric acid (10\%, v/v); Extraction buffer: $30 \mathrm{~mL} 0.1 \mathrm{M} \mathrm{Na}_{2} \mathrm{HPO}_{4}$, $150 \mathrm{~mL} \mathrm{H}_{2} \mathrm{O}$ and $270 \mathrm{~mL}$ methanol to form $450 \mathrm{~mL}$ extraction buffer.

\subsection{Instrumentation}

UV-3010 spectrophotometer (Hitachi, Japan) was used for the UV-visible absorption measurements. ELISA plates were washed with a microtiter plate washer DEM-3 (Tuopu, China). Absorbance was measured at a wavelength of $450 \mathrm{~nm}$ using the Wallac 1420 VICTOR3 multilabel counter (Perkin Elmer Ltd., US).

\subsection{Hapten Synthesis}

Two haptens used for immunizing and coating antigen are shown in Scheme 1. They were synthesized by the same procedure using corresponding commercial start materials. The following subsections describe the synthesis procedure and the identification of haptens.

\subsubsection{4-((2,4-Diaminophenyl)diazenyl)benzoic acid (Hapten 1)}

To a stirring solution of 4-aminobenzoic acid $(0.411 \mathrm{~g}, 3 \mathrm{mmol})$ in water $(10 \mathrm{~mL})$, cooled in an ice water bath, $0.1 \mathrm{M}$ hydrochloric acid $(10 \mathrm{~mL})$ was added to keep $\mathrm{pH}$ at 3-4, followed by dropwise addition of sodium nitrite $(0.228 \mathrm{~g})$ dissolved in water $(1 \mathrm{~mL})$. The mixture was stirred for $2 \mathrm{~h}$, and then $m$-phenylenediamine $(0.356 \mathrm{~g}, 3.3 \mathrm{mmol})$ dissolved in water $(5 \mathrm{~mL}), \mathrm{pH}$ adjusted to $6-7$ with hydro-chloric acid, and cooled with ice water was added dropwise. After stirring for $2 \mathrm{~h}$, the mixture was kept at $4{ }^{\circ} \mathrm{C}$ overnight and filtered to collect the residue. The crude product was purified by silica gel column chromatography (chloroform-methanol $=15: 1, \mathrm{v}: \mathrm{v})$. Yield: $62 \%$. TLC $R_{f}=0.5\left(\mathrm{CHCl}_{3}: \mathrm{MeOH}=15: 1\right)$; MS (APCI positive) $m / z: 257[\mathrm{M}+\mathrm{H}]^{+} .{ }^{1} \mathrm{H}-\mathrm{NMR}\left(\mathrm{DMSO}-d_{6}, 600 \mathrm{MHz}\right) \delta: 8.79(\mathrm{~s}, 1 \mathrm{H}), 8.58(\mathrm{~s}, 1 \mathrm{H}), 7.95(\mathrm{~d}$, $2 \mathrm{H}), 7.82(\mathrm{~d}, 4 \mathrm{H}), 6.50(\mathrm{~d}, 4 \mathrm{H}), 3.59(\mathrm{~d}, 2 \mathrm{H})$.

\subsubsection{2-(4-((2,4-Diaminophenyl) diazenyl)phenyl)acetic acid (Hapten 2)}

Hapten 2 was synthesized using 2-(4-aminophenyl)acetic acid as the starting compound (Scheme 1). The procedure is the same as the synthesis of Hapten 1 above. TLC $R_{f}=0.5\left(\mathrm{CHCl}_{3}: \mathrm{MeOH}=15: 1\right)$. MS (APCI positive) $m / z: 271[\mathrm{M}+\mathrm{H}]^{+} .{ }^{1} \mathrm{H}-\mathrm{NMR}\left(\mathrm{DMSO}-d_{6}, 600 \mathrm{MHz}\right) \delta: 7.61(\mathrm{~d}, 2 \mathrm{H}), 7.29-7.36(\mathrm{~d}, 4 \mathrm{H})$, $5.86-6.00(\mathrm{~d}, 2 \mathrm{H})$ 


\subsection{Preparation of Immunogen and Coating Antigen}

The hapten was conjugated to BSA (bovine serum albumin; for use as immunogen) and OVA (ovalbumin; for use as coating antigen) by the active ester method [12]. Briefly, to the each hapten $(0.1 \mathrm{mmol})$ in DMF $(500 \mu \mathrm{L})$, DCC $(0.2 \mathrm{mmol})$, followed by NHS $(0.2 \mathrm{mmol})$ was added slowly. This activation reaction was carried out overnight at $4{ }^{\circ} \mathrm{C}$ with continuous stirring. The reaction mixture was centrifuged $(10,000 \mathrm{~g}, 10 \mathrm{~min})$ and, the supernatant was added very slowly to a BSA solution (150 $\mathrm{mg}$ BSA or ovalbumin dissolved in $15 \mathrm{~mL}$ PBS). The mixture was stirred overnight at $4{ }^{\circ} \mathrm{C}$ to complete the conjugation reaction. The mixture was then dialyzed against phosphate buffer $(0.01 \mathrm{~mol} / \mathrm{L}, \mathrm{pH} 7.4)$ for 3 days (three changes of buffer per day). The immunogen and coating antigen were characterized by the ultraviolet spectrophotometers [13]. The obtained immunogen hapten-BSA or coating antigen hapten-OVA were stored at $-20^{\circ} \mathrm{C}$ until use.

\subsection{Immunization Protocol}

The intramuscular injection was given to one New Zealand white rabbits for each immunogen, total two rabbits were used to raise antibody. In brief, each immunogen hapten-BSA $(0.5 \mathrm{mg})$ was dissolved in saline and emulsified with an equal volume of Freund's complete adjuvant. Two New Zealand rabbits weighing 1.5-2.0 kg were immunized four times using emulsified Hapten 1-BSA, Hapten 2-BSA, respectively, at intervals of 21 days by the Guangdong Medical Laboratory Animal Center. The rabbits were blood sampled to detect the presence of antibodies to chrysoidine using an indirect ELISA on the eighth day after each immunization, starting 40 days after the first injection. Bleeding of animals was performed 10 days after the fouth immunization and the collected antisera, named $\mathrm{Ab} 1$ for that raised from Hapten 1-OVA, Ab 2 for that raised from Hapten 2-OVA, respectively. Antisera were divided into aliquots $(1 \mathrm{~mL})$ and stored at $-20{ }^{\circ} \mathrm{C}$ until use.

\subsection{Indirect Competitive ELISA}

Checkerboard assays, in which antibodies were titrated against various amounts of the coating antigen, were used to measure the reactivity of antibodies and to select an appropriate antigen coating and antibody dilutions for competitive indirect assays. From the results of the checkerboard assays, two antibodies were selected as the most suitable ones. Then, to select the most suitable coating antigen, competitive assays were performed under various combinations at several chrysoidine concentration levels. The concentrations of the antibodies and the coating antigen chosen were further optimized.

The procedure for the competitive assay was as follows. Microtiter plates were coated with hapten-OVA (100-1000 ng/mL, $100 \mu \mathrm{L} /$ well) in carbonate-bicarbonate buffer $(50 \mathrm{mM}, \mathrm{pH} 9.6)$ by overnight incubation at $4{ }^{\circ} \mathrm{C}$. The plates were blocked with blocking solution by incubation for $3 \mathrm{~h}$. Serial dilution of the analyte in methanol-PBST (1:9, v:v, $50 \mu \mathrm{L} /$ well) were added, followed by $50 \mu \mathrm{L} /$ well of antibody diluted $(1 / 1,000-1 / 10,000)$ with PBST solution. After incubation for about 30-60 min, $100 \mu \mathrm{L} /$ well of a diluted (1/10,000) goat anti-rabbit IgG-HRP was added. The mixture was incubated for $60 \mathrm{~min}$, and $100 \mu \mathrm{L} /$ well of a TMB solution was added. The reaction was stopped after an appropriate time (typically $8 \mathrm{~min}$ ) by adding $10 \%(\mathrm{v}: \mathrm{v}) \mathrm{H} 2 \mathrm{SO} 4(50 \mu \mathrm{L})$, and the absorbance was read at $450 \mathrm{~nm}$. 


\subsection{Cross-Reactivity}

Specificity of the optimized assay was tested by measuring the cross-reactivity using a group of structurally related dyes. Twenty-four compounds were selected for testing the cross-reactivity (CR) (Table 1). The CR was calculated as follows: $\mathrm{CR}(\%)=\left[\mathrm{IC}_{50}(\right.$ chrysoidine $) / \mathrm{IC}_{50}$ (interferent) $] \times 100$.

\subsection{Sample Preparation}

The soybean milk film samples were obtained from a local food supplier and were homogenized. To the soybean milk film sample (2.5 g) chrysoidine standard (112.5, 225, $450 \mathrm{ng})$ was added in methanol $(100 \mu \mathrm{L})$. After setting aside for $1 \mathrm{~h}$, extraction buffer $(25 \mathrm{~mL})$ was infused into the sample and the extraction mixture was shaken for $20 \mathrm{~min}$ and supersonicated for $20 \mathrm{~min}$, followed by centrifugation $(10,000 \mathrm{~g})$ for $10 \mathrm{~min}$. The supernatant was collected and diluted appropriately with PBST to be measured by icELISA. For each sample, three separate extractions were performed and each sample was determined in five replicates. Negative samples confirmed by HPLC were extracted in the same way and used as a blank.

\subsection{HPLC Analysis}

Samples were extracted as described above just without the last PBST dilution step, after a filtration with $0.45 \mu \mathrm{m}$ membrane chrysoidine was analyzed on a Waters HPLC system equipped with a Waters X-Brige-C18 column $(4.6 \times 150 \mathrm{~mm}, 5 \mu \mathrm{m})$. The injection volume was $10 \mu \mathrm{L}$. The mobile phase consisted of methanol and $5 \mathrm{M}$ ammonium acetate-acetic acid buffer ( $\mathrm{pH} 4.17$ ) at a volume ratio of $55: 45$. The flow rate was $1.0 \mathrm{~mL} / \mathrm{min}$. The detection wavelength was set at $458 \mathrm{~nm}$. The retention time of chrysoidine was $6.7 \mathrm{~min}$. The concentrations of chrysoidine were calculated by calibration with the peak areas of external chrysoidine standard.

\section{Conclusions}

In this work, antibodies against chrysoidine were prepared for the first time and used to develop an indirect competitive ELISA. Two types of hapten have been synthesized and used to produce polyclonal antibodies and coating antigens. Use of the antibody against the immunogen with two-carbon-atom spacer arm and the heterologous coating antigen with one-carbon-atom spacer arm resulted in the high sensitivity and specificity. The $\mathrm{IC}_{50}$ and $\mathrm{LOD}$ values of the assay for chrysoidine are 0.33 and $0.04 \mathrm{ng} / \mathrm{mL}$, respectively. All tested dyes exhibited no cross-reactivity with the antibody to chrysoidine. In addition, high recovery rates $(102.1 \%-106.5 \%)$ were obtained when this assay was applied to the fortified samples. The ELISA method was also compared to HPLC with an excellent correlation. Therefore, the icELISA could be a feasible quantitative/screening method for chrysoidine analysis in food samples.

\section{Acknowledgments}

This work was supported by National Department Public Benefit Research Foundation (201003008-08), SCAU Principal Fund on International Coorperation, China Guangdong Provincial 
Science and Technology Projects (cgzhzd1005, cgzhzd0808, 2009B040500002) and the NSFC-RFBR Joint Grant (21010206, 11-04-91189).

\section{References and Notes}

1. Doh-ura, K.; Tamura, K.; Karube, Y.; Naito, M.; Tsuruo, T.; Kataoka, Y. Chelating compound, chrysoidine, is more effective in both antiprion activity and brain endothelial permeability than quinacrine. Cell. Mol. Neurobiol. 2007, 27, 303-316.

2. Gui, W.J.; Xu, Y.; Shou, L.F.; Zhu, G.N.; Ren, Y.P. Liquid chromatography-tandem mass spectrometry for the determination of chrysoidine in yellow-fin tuna. Food Chem. 2010, 122, 1230-1234.

3. Tonogai, Y.; Ogawa, S.; Ito, Y.; Iwaida, M. Actual survey on TLm (median tolerance limit) values of environmental pollutants, especially on amines, nitriles, aromatic nitrogen compounds and artificial dyes. J. Toxicol. Sci. 1982, 7, 193-203.

4. Reyns, T.; Fraselle, S.; Laza, D.; Van Loco, J. Rapid method for the confirmatory analysis of chrysoidine in aquaculture products by ultra-performance liquid chromatography-tandem mass spectrometry. Biomed. Chromatogr. 2010, 24, 982-989.

5. Lin, Q. Simultaneous determination of chrysoidine and auramine O in bean products by HPLC. Chin. J. Chromatogr. 2007, 25, 776-777.

6. Ji, S.-J.; Zhang, Q.-H.; Shen, Y.-X. Screening for colour developer and optimization of reaction conditions for fast determination of basic orange II in foods. Food Sci. 2010, 31, 394-398.

7. Du, X.-L.; Dong, Y.-X.; Li, K.-Q. Determination of basic orange in dried beancurd stick. Food Sci. Technol. 2011, 36, 269-270.

8. Wang, X.; Song, G.X.; Wu, W.P.; Zhao, J.F.; Hu, Y.M. Determination of the food colorant, chrysoidine, in fish by GC-MS. Chromatographia 2008, 68, 659-662.

9. Standardization Administration of the People's Republic of China. Determination of Forbiddenmaterialsin Food: Dyes of Basic Orange-HIGH Performance Liquid Chromatography Methods; China Standard Press: Beijing, China, 2009; GB/T 23496-2009.

10. Morgan, P.E.; Fisher, D.S.; Evers, R.; Flanagan, R.J. A rapid and simple assay for lamotrigine in serum/plasma by HPLC, and comparison with an immunoassay. Biomed. Chromatogr. 2011, 25, 775-778.

11. Wang, Y.; Yang, H.; Wang, B.; Deng, A. A sensitive and selective direct competitive enzyme-linked immunosorbent assay for fast detection of Sudan I in food samples. J. Sci. Food Agric. 2011, 91, 1836-1842.

12. Lei, H.; Shen, Y.; Song, L.; Yang, J.; Chevallier, O.P.; Haughey, S.A.; Wang, H.; Sun, Y.; Elliott, C.T. Hapten synthesis and antibody production for the development of a melamine immunoassay. Anal. Chim. Acta 2010, 665, 84-90.

13. Lei, H.; Su, R.; Haughey, S.A.; Wang, Q.; Xu, Z.; Yang, J.; Shen, Y.; Wang, H.; Jiang, Y.; Sun, Y. Development of a specifically enhanced enzyme-linked immunosorbent assay for the detection of melamine in milk. Molecules 2011, 16, 5591-5603. 
14. Ferreira, J.L.; Eliasberg, S.J.; Edmonds, P.; Harrison, M.A. Comparison of the mouse bioassay and enzyme-linked immunosorbent assay procedures for the detection of type A botulinal toxin in food. J. Food Prot. 2004, 67, 203-206.

15. Moreno, M.J.; D'Arienzo, P.; Manclus, J.J.; Montoya, A. Development of monoclonal antibody-based immunoassays for the analysis of bisphenol A in canned vegetables. J. Environ. Sci. Health B 2011, 46, 509-517.

16. Salado-Rasmussen, K.; Theilgaard, Z.P.; Chiduo, M.; Pedersen, C.; Gerstoft, J.; Katzenstein, T.L. Good performance of an immunoassay based method for nevirapine measurements in human breast milk. Clin. Chem. Lab. Med. 2011, 49, 1171-1175.

17. Schwope, D.M.; Milman, G.; Huestis, M.A. Validation of an enzyme immunoassay for detection and semiquantification of cannabinoids in oral fluid. Clin. Chem. 2010, 56, 1007-1014.

18. Song, Y.; Ge, Y.; Zhang, Y.; Liu, B.; Lu, Y.; Dong, T.; Wang, S. Hapten synthesis and enzyme-linked immunosorbent assay for phosmet residues: Assay optimization and investigation of matrix effects from different food samples. Anal. Bioanal.Chem. 2009, 393, 2001-2008.

19. Yuan, M.; Liu, B.; Liu, E.; Sheng, W.; Zhang, Y.; Crossan, A.; Kennedy, I.; Wang, S. Immunoassay for phenylurea herbicides: Application of molecular modeling and quantitative structure-activity relationship analysis on an antigen-antibody interaction study. Anal. Chem. 2011, $83,4767-4774$.

20. Xu, Z.L.; Shen, Y.D.; Beier, R.C.; Yang, J.Y.; Lei, H.T.; Wang, H.; Sun, Y.M. Application of computer-assisted molecular modeling for immunoassay of low molecular weight food contaminants: A review. Anal. Chim. Acta 2009, 647, 125-136.

21. El-Gendy, K.S.; Aly, N.M.; Mosallam, E.M.; Salama, A.K. Preparation of antibodies and development of an enzyme immunoassay for determination of atrazine in environmental samples. J. Environ. Sci. Health B 2011, 46, 321-327.

22. Han, D.; Yu, M.; Knopp, D.; Niessner, R.; Wu, M.; Deng, A. Development of a highly sensitive and specific enzyme-linked immunosorbent assay for detection of Sudan I in food samples. J. Agric. Food. Chem. 2007, 55, 6424-6430.

23. Ju, C.; Tang, Y.; Fan, H.; Chen, J. Enzyme-linked immunosorbent assay (ELISA) using a specific monoclonal antibody as a new tool to detect Sudan dyes and Para red. Anal. Chim. Acta 2008, 621, 200-206.

24. Xu, J.; Zhang, Y.; Yi, J.; Meng, M.; Wan, Y.; Feng, C.; Wang, S.; Lu, X.; Xi, R. Preparation of anti-Sudan red monoclonal antibody and development of an indirect competitive enzyme-linked immunosorbent assay for detection of Sudan red in chilli jam and chilli oil. Analyst 2010, 135, 2566-2572.

25. Wang, Y.; Wei, D.; Yang, H.; Yang, Y.; Xing, W.; Li, Y.; Deng, A. Development of a highly sensitive and specific monoclonal antibody-based enzyme-linked immunosorbent assay (ELISA) for detection of Sudan I in food samples. Talanta 2009, 77, 1783-1789. 
26. Lei, H.; Xue, G.; Yu, C.; Haughey, S.A.; Eremin, S.A.; Sun, Y.; Wang, Z.; Xu, Z.; Wang, H.; Shen, Y.S.; Wu, Q. Polarization as a tool for the detection of a widely used herbicide, butachlor, in polluted waters. Anal. Methods 2011, doi:10.1039/C1031AY05347G.

Sample Availability: Samples of the compounds Sunset yellow, Acid Yellow 23, Orangeim, Acid Red 94, Auramine O, 1-(4-nitrophenylazo)-2-naphtho and Sudan Red I, etc., are available from the authors.

(C) 2011 by the authors; licensee MDPI, Basel, Switzerland. This article is an open access article distributed under the terms and conditions of the Creative Commons Attribution license (http://creativecommons.org/licenses/by/3.0/). 